\title{
Установление взаимосвязи микроструктуры и термоэлектрических свойств кристаллов высшего силицида марганца, легированных германием
}

\author{
(C) А.С. Орехов ${ }^{1,2}$, В.В. Клечковская ${ }^{1}$, Е.В. Ракова ${ }^{1}$, Ф.Ю. Соломкин ${ }^{3}$, С.В. Новиков ${ }^{3}$, \\ Л.В. Бочков ${ }^{3}$, Г.Н. Исаченко ${ }^{3,4}$ \\ ${ }^{1}$ Институт кристаллографии им. А.В. Шубникова ФНИЦ „Кристаллография и фотоника“ Российской академии наук, \\ 119333 Москва, Россия \\ ${ }^{2}$ Национальный исследовательский центр „Курчатовский институт“, \\ 123182 Москва, Россия \\ ${ }^{3}$ Физико-технический институт им. А.Ф. Иоффе Российской академии наук, \\ 194021 Санкт-Петербург, Россия \\ ${ }^{4}$ Санкт-Петербургский национальный исследовательский университет информационных технологий, механики и оптики, \\ 197101 Санкт-Петербург, Россия \\ E-mail: andrey.orekhov@gmail.com
}

(Получена 27 декабря 2016 г. Принята к печати 12 января 2017 г.)

\begin{abstract}
Природа формирования включений фазы моносилицида марганца в процессе роста кристаллов высшего силицида марганца до сих пор детально не изучена. На их количество (плотность) значительное влияние оказывают легирующие примеси. В работе была исследована структура кристаллов высшего силицида марганца, выращенных с различным содержанием германия в качестве легирующего элемента. Было выявлено, что увеличение концентрации германия до 1 ат\% приводит к дроблению слоистых выделений моносилицида марганца и, одновременно с этим, к значительным изменениям термоэлектрических свойств кристалла высшего силицида марганца. Полученные данные об изменениях микроструктуры, возникающих в зависимости от концентрации германия, могут быть полезны для понимания механизма формирования фазы моносилицида марганца при росте кристаллов высшего силицида марганца.
\end{abstract}

DOI: 10.21883/FTP.2017.07.44644.30

\section{1. Введение}

Интерес исследователей к кристаллам высшего силицида марганца (ВСМ) связан с их высокими термоэлектрическими характеристиками в среднетемпературном диапазоне, а также экологичностью и дешевизной исходных компонентов. На рис. 1 представлена типичная зависимость термоэдс и электропроводности кристалла ВСМ при нагреве до $850 \mathrm{~K}$. Высший силицид марганца соответствует композиционному составу $\mathrm{MnSi}_{x}(x \sim 1.7)$. Его кристаллическая решетка относится к структурному типу $\mathrm{TiSi}_{2}$. Считается, что несоразмерность подрешеток кремния и марганца приводит к образованию серии фаз высших силицидов марганца, так называемого ряда фаз Новотного - $\mathrm{Mn}_{4} \mathrm{Si}_{7}$, $\mathrm{Mn}_{11} \mathrm{Si}_{19}, \mathrm{Mn}_{15} \mathrm{Si}_{26}, \mathrm{Mn}_{27} \mathrm{Si}_{47}$ [1-3]. Кристаллические ячейки всех фаз ВСМ имеют близкий мотив: атомы марганца располагаются подобно атомам Sn в тетрагональ-

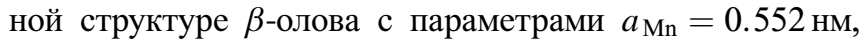
$c_{\mathrm{Mn}}=0.437 \mathrm{нм}$ (рис. 1). Атомы кремния, заполняя промежутки в тетрагональной подрешетке марганца, формируют двойную спираль с периодом $c_{\mathrm{Si}}$, приблизительно равным четырем периодам $c_{\mathrm{Mn}}$. Известно, что характерной особенностью микроструктуры кристаллов ВСМ, выращенных методами Бриджмена или Чохральского, является выделение кубической фазы моносилицида марганца $\mathrm{MnSi}$ в виде ламелей, ориентированных перпендикулярно оси $[001]_{\mathrm{BCM}}$ [4-7]. Таким образом, вдоль оси $c_{\text {HMS }}$ формируется так называемая „барьерная“ структура -BCM-MnSi-BCM-MnSi-. Фаза моносилицида марганца обладает высокой теплопроводностью и низким значением термоэлектрической добротности и тем самым негативно влияет на термоэлектрические свойства кристалла ВСМ в целом. Природа появления фазы $\mathrm{MnSi}$ при росте кристаллов и пленок ВСМ в настоящий момент детально не изучена. Однако в процессе оптимизации физических свойств кристалла ВСМ путем введения легирующих примесей было выявлено, что германий приводит к дроблению слоистых выделений моносилицида марганца и, одновременно с этим, к значительному изменению термоэлектрических свойств кристалла ВСМ. Однако ввиду ограничения разрешающей способности применявшихся ранее диагностических методов, процесс формирования фазы $\mathrm{MnSi}$ в различных условиях эксперимента не был детально проанализирован.

Цель данной работы заключается в выявлении особенностей микроструктуры кристаллов высшего силицида марганца, легированных германием, с помощью высокоразрешающей растровой электронной микроскопии.

\section{2. Материалы и методы}

Была исследована микроструктура кристаллов высшего силицида марганца, легированных германием в концентрации 0.1, 0.2 и 1 ат\%. Кристаллы были выращены по методу Бриджмена, подробное описание синтеза 

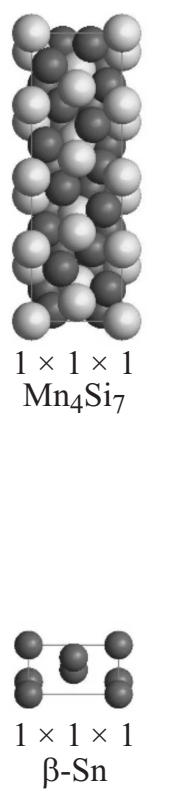

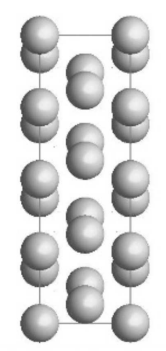

Mn sub-cell $a=5.52 \AA$

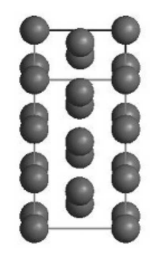

$4 \times 1 \times 1$ $\beta-\mathrm{Sn}$

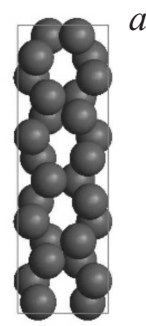

Si sub-cell

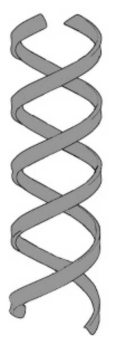

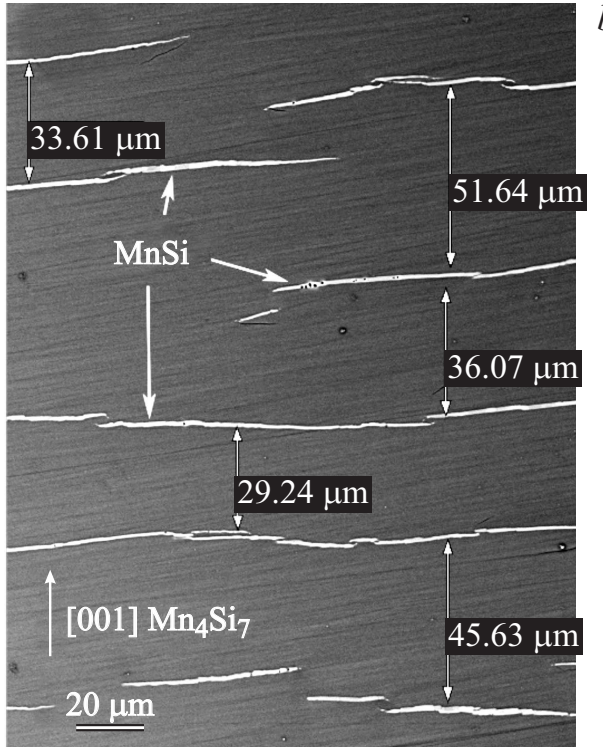

$b$

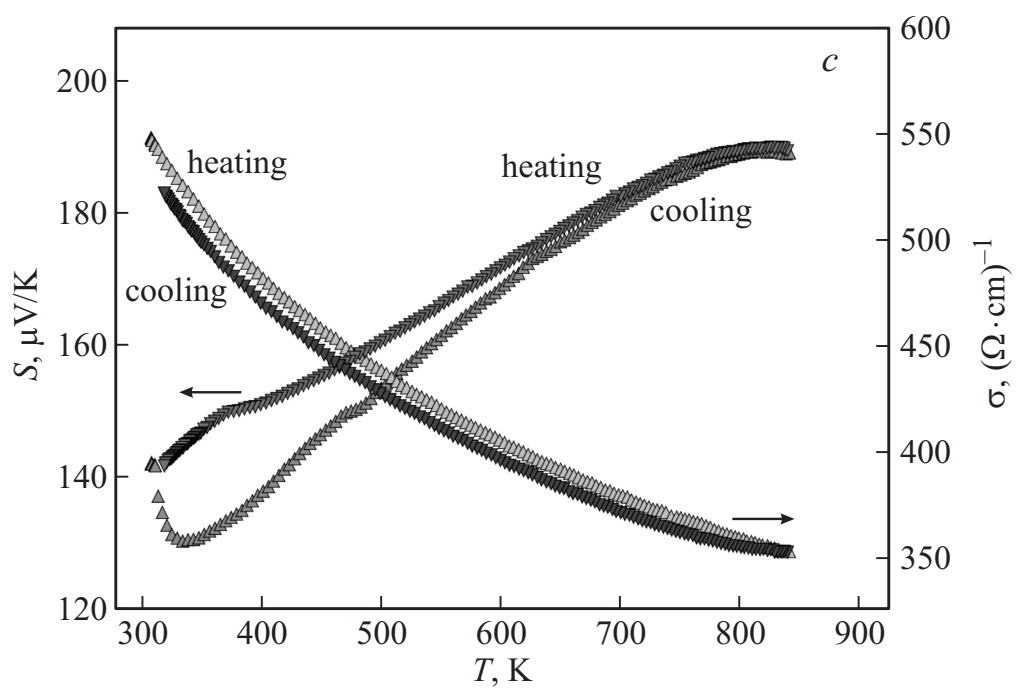

Рис. 1. Модель кристаллической ячейки $\mathrm{BCM} \mathrm{Mn}_{4} \mathrm{Si}_{7}(a)$, которую можно представить в виде подрешетки марганца (структурный тип $\beta$-Sn) и двойной спиралевидной подрешетки кремния. РЭМ-изображение микроструктуры кристалла ВСМ с выделениями $\mathrm{MnSi}$ перпендикулярно оси [001]BCM $(b)$. Термоэлектрические свойства нелегированного кристалла ВCM $(c)$.

приведено в работе [8]. Поперечные срезы образцов предварительно полировались абразивными алмазными суспензиями с размером частиц от 15 до 0.1 мкм. Исследования проводились в растровом электронном микроскопе FEI HELIOS NanoLab 600 с термоэмиссионным источником электронов в режиме обратно рассеянных электронов. Как известно, контраст изображения в данном режиме съемки обратно пропорционален атомному номеру вещества и позволяет выявлять отличия в составе выделений и монокристалла [9].

\section{3. Экспериментальные результаты}

На рис. 2 приведены изображения характерных фрагментов микроструктуры нелегированного образца (рис. $2, a)$ и легированных германием в концентрации 0.1 (рис. 2,b), 0.2 (рис. 2,c) и 1 ат\% (рис. 2, $d$ ). Видно, что добавление германия в расплав по мере увеличения его содержания приводит к утоньшению прослоек $\mathrm{MnSi}$, уменьшению расстояния между ними и постепенному их дроблению и исчезновению. Следует отметить, что при этом наблюдалась ориентация кристаллических выделений фазы MnSi не только перпендикулярно оси $[001]_{\mathrm{BCM}}$, как было известно ранее [4], а также и вдоль оси $c_{\text {Всм. }}$ Наиболее отчетливо прослойки $\mathrm{MnSi}$ видны на рис. $2, b$ и $c$. Их толщина уменьшается с 1.3 до 0.1 мкм и менее по мере увеличения содержания германия. Процесс дробления слоистых выделений MnSi подробнее зафиксирован на изображениях с большим увеличением от образцов с концентрацией Ge 0.1 и 0.2 ат\% (рис. $2, e, f$ ). Полосчатые выделения начинают дробиться на отдельные частицы 
размерами 140-160 нм и уменьшаются до 100 нм и менее при увеличении концентрации германия. При концентрации германия 0.01 ат\% выделения $\mathrm{MnSi}$ представляют собой тончайшие плоские структуры, вертикально ориентированные относительно плоскости шлифа/рисунка (рис. 2,d). Данные выделения переходят в рентгеноаморфное состояние и могут быть зарегистрированы только методами растровой и просвечивающей электронной микроскопии.

В ходе работы, кроме исследования микроструктуры, были выполнены измерения термоэлектрических свойств на установке, описанной в [10]. На рис. 3 приведены результаты измерений термоэлектрических
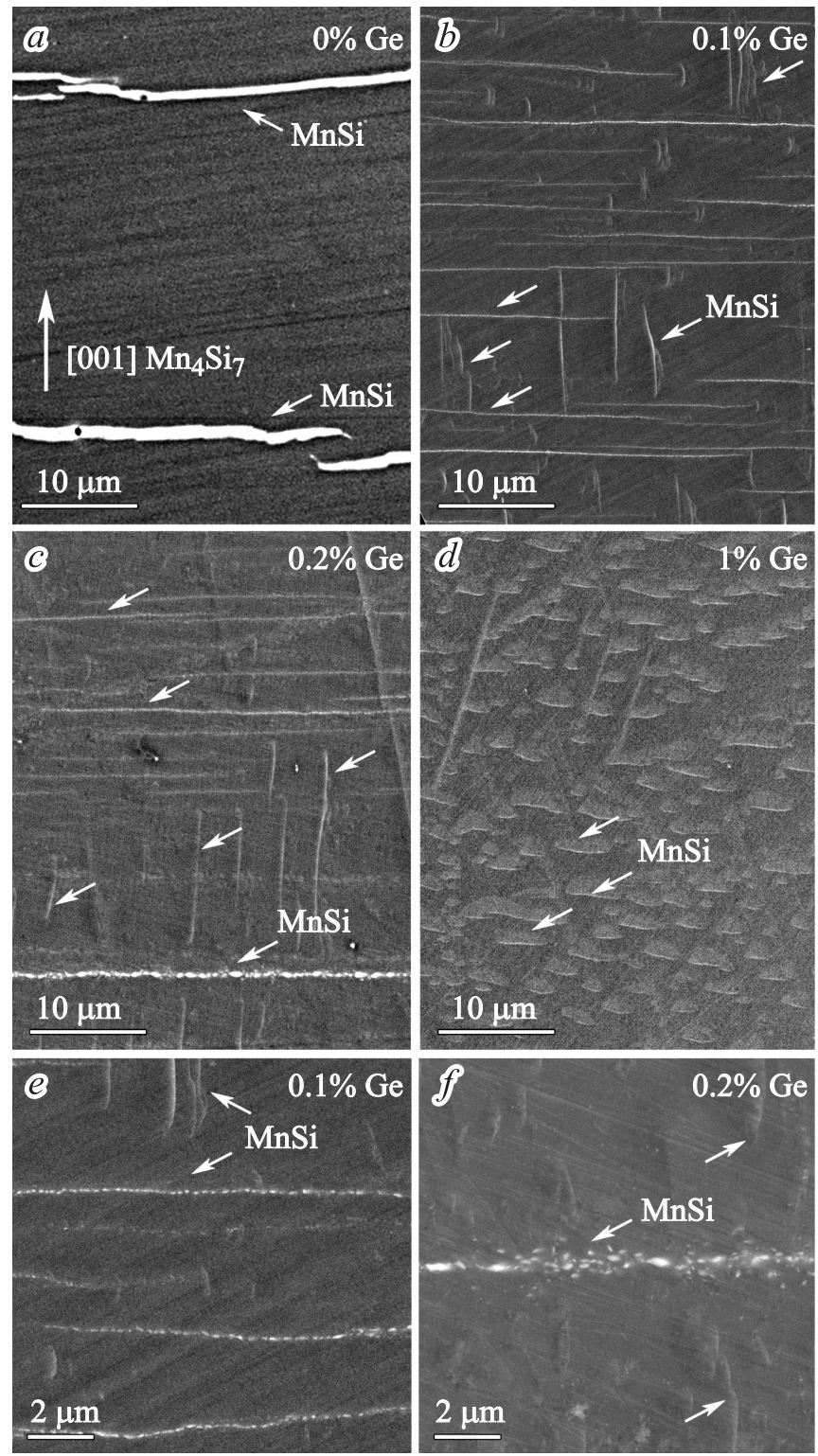

Pис. 2. РЭМ-изображения в режиме $Z$-контраста характерных фрагментов микроструктуры нелегированного $(a)$ и легированных кристаллов ВCM с концентрацией Ge $0.1(b), 0.2(c)$, 1 ат\% $(d)$. Увеличенные фрагменты микроструктуры, выявляющие дробление фазы $\mathrm{MnSi}(e, f)$.
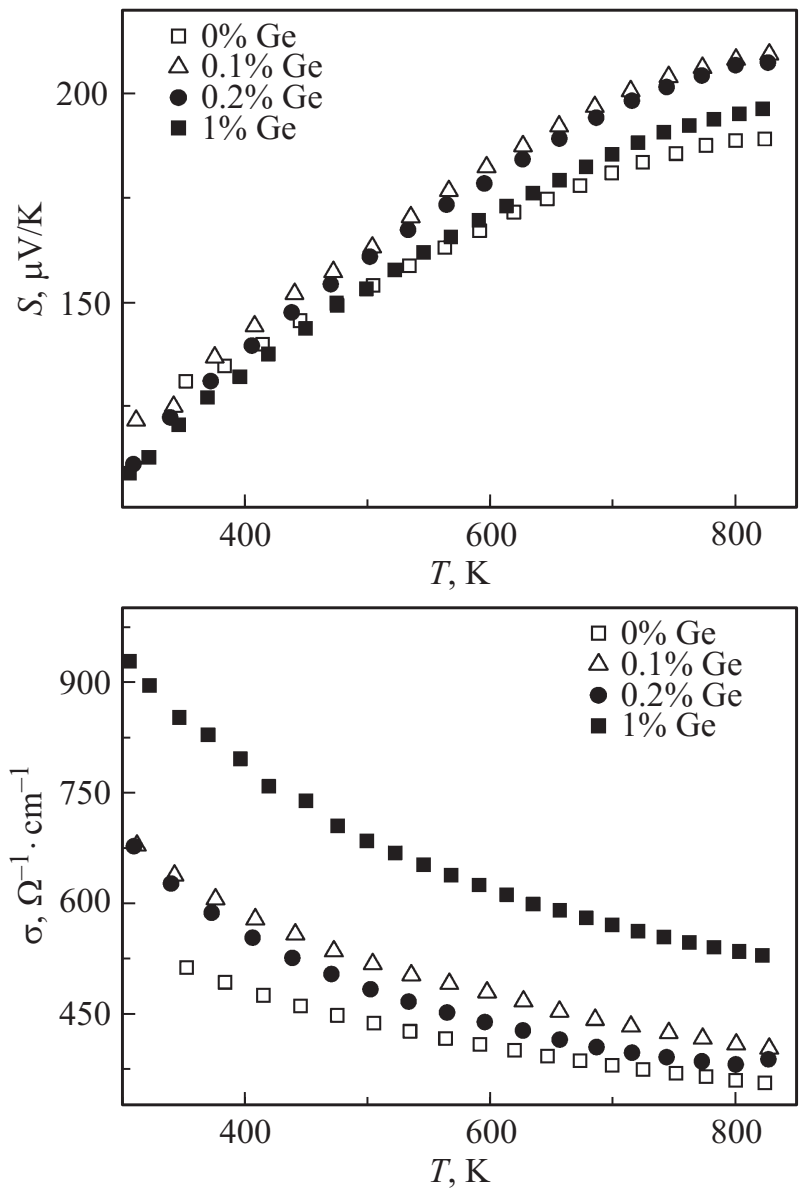

Рис. 3. Температурные зависимости коэффициента термоэдс $(S)$ и удельной электрической проводимости $(\sigma)$ образцов ВСМ с различной степенью легирования.

свойств кристаллов ВСМ с различной степенью легирования. Видно, что термоэдс образцов ВСМ несколько увеличено у легированных образцов, а проводимость кристаллов ВСМ заметно растет с увеличением содержания Ge. Как было показано ранее [8], с ростом концентрации Ge растет значение термоэлектрической эффективности $Z T$ - величины, пропорциональной кпд термоэлектрического преобразования энергии, $Z T=S^{2} \sigma / \kappa$. Здесь $S-$ коэффициент термоэдс, $\sigma-$ удельная электрическая проводимость, $\kappa-$ удельная теплопроводность.

\section{4. Заключение}

Результаты проведенных исследований показали, что пластинчатые выделения фазы моносилицида марганца, присутствующие в легированных кристаллах ВСМ, могут ориентироваться не только в плоскости, перпендикулярной оси $c_{\text {ВСм}}$, но также и параллельно оси $c_{\text {Всм}}$. Увеличение концентрации германия до 1 ат\% приводит к дроблению выделений моносилицида марганца. Одновременно с разрушением выделений $\mathrm{MnSi}$ наблюдается 
значительное улучшение термоэлектрических свойств кристалла ВСМ. Полученные экспериментальные данные не могут быть описаны в рамках существующей модели возникновения фазы $\mathrm{MnSi}$ при росте кристаллов высшего силицида марганца. Для получения дополнительных структурных данных на атомном уровне авторы планируют продолжить исследование данной серии образцов методами высокоразрешающей просвечивающей электронной микроскопии. Наблюдаемые изменения микроструктуры включений моносилицида в зависимости от концентрации легирующего элемента (германия) могут быть полезны для уточнения существующей модели формирования этой фазы, в соответствии с которой данный процесс связан с накоплением несоразмерности между подрешетками марганца и кремния при росте кристалла ВСМ.

Работа выполнена при частичной финансовой поддержке стипендии Президента РФ молодым ученым и аспирантам № СП-1404.2016.1 с использованием оборудования ЦКП ИК РАН и ресурсного центра зондовой и электронной микроскопии Курчатовского комплекса НБИКС-технологий.

\section{Список литературы}

[1] U. Gottlieb, A. Sulpice, B. Lambert-Andron, O. Laborde. J. Alloys Comp., 361 (1-2), 13 (2003).

[2] O. Schwomma, A. Preisinger, H. Nowotny, A. Wittmann. Monatsh. Chem., 95 (6), 1527 (1964).

[3] O. Schwomma, H. Nowotny, A. Wittmann. Monatsh. Chem., 94 (4), 681 (1963).

[4] L.M. Levinson. J. Solid State Chem., 6, 126 (1973).

[5] А.С. Орехов, Е.И. Суворова. Кристаллография, 59 (1), 83 (2014). [Eng. version: A.S. Orekhov, E.I. Suvorova. Crystallography Reports, 59 (1), 78 (2014).]

[6] А.С. Орехов, Т.С. Камилов, А.С. Орехов, Н.А. Архарова, Е.В. Ракова, В.В. Клечковская. Росс. нанотехнологии, 11 (5-6), 30 (2016). [Eng. version: A.S. Orekhov, T.S. Kamilov, A.S. Orekhov, N.A. Arkharova, E.V. Rakova, V.V. Klechkovskaya. Nanotech. in Rus., 11 (9-10), 610 (2016).]

[7] Z.M. Wang, Y.D. Wu, Y.J. He. Int. J. Mod. Phys. B, 18 (1), 87 (2004).

[8] I. Aoyama, M.I. Fedorov, V.K. Zaitsev, F.Yu. Solomkin, I.S. Eremin, A.Yu. Samunin, M. Mukoujima, S. Sano, T. Tsuji. Jpn. J. Appl. Phys., 44 (12), 8562 (2005).

[9] J. Goldstein, D.E. Newbury, D.C. Joy, C.E. Lyman, P. Echlin, E. Lifshin, L. Sawyer, J.R. Michael. Scanning Electron Microscopy and X-ray Microanalysis (Springer Science \& Business Media, 2003) p. 690.

[10] A.T. Burkov, A. Heinrich, P.P. Konstantinov, T. Nakama, K. Yagasaki. Meas. Sci. Technol., 12, 264 (2001).

\section{The dependence of microstructure and thermoelectric properties of higher manganese silicide crystals doped by germanium}

\section{A.S. Orekhov ${ }^{\mathbf{1}, 2}$, V.V. Klechkovskaya ${ }^{1}$, E.V. Rakova ${ }^{\mathbf{1}}$, F.Yu. Solomkin ${ }^{3}$, S.V. Novikov ${ }^{3}$, L.V. Bochkov ${ }^{3}$, G.N. Isachenko ${ }^{3,4}$}

\author{
${ }^{1}$ Shubnikov Institute of Crystallography \\ of Federal Research Centre \\ "Crystallography and Photonics“ \\ of Russian Academy of Science, \\ 119333 Moscow, Russia \\ ${ }^{2}$ National Research Centre „Kurchatov Institute“, \\ 123182 Moscow, Russia \\ ${ }^{3}$ loffe Institute, \\ 194021 St. Petersburg, Russia \\ ${ }^{4}$ Information Technologies, \\ Mechanics and Optics University, \\ 197101 St. Petersburg, Russia
}

\begin{abstract}
The nature of the manganese monosilicide inclusions formation during higher manganese silicide crystals-growth is not studied in detail. The amount and density of the inclusions is strongly influenced by dopants. In this paper the structure of the HMS crystal with different content of germanium as dopant was studied. It was found that germanium concentration increasing up to 1 at $\%$ leads to manganese monosilicide crushing and is attended with a significant changing of the HMS thermoelectric properties. This microstructure analysis of the HMS crystals with various germanium concentration is necessary for understanding of the mechanism of manganese monosilicide formation during higher manganese silicide crystal growth.
\end{abstract}

